\title{
SPONTANEOUS OSTEONECROSIS IN AN ATHLETE'S KNEE TREATED USING A HYPERBARIC CHAMBER: CASE REPORT AND REVIEW OF THE LITERATURE
}

Guilherme Campos Barroso', Thiago Fuchs², Edilson Thiele ${ }^{3}$, Mônica Nunes Lima ${ }^{4}$

\begin{abstract}
Osteonecrosis is a clinical syndrome characterized by osseous necrosis of a load-bearing portion of the femoral condyle, followed by subchondral fracturing, subsequent segmental collapse and arthrosis. It most frequently affects obese women over the age of 55 years. Its treatment is still a matter of controversy in the literature. The authors report the case of a 24 -year-old male patient who was a professional soccer player, who presented with a complaint of knee pain one day after physical activity. Imaging examinations performed early on already de-
\end{abstract}

monstrated the start of the lesion. The treatment, which was successful, used the following: withdrawal of support, physiotherapy, medications (such as NSAIDs and bisphosphonates) and a hyperbaric chamber. Although hyperbaric chamber therapy is new, its use in association with drug therapy and withdrawal of support may bring good results in treating idiopathic osteonecrosis, even for athletes with high physical demands. However, there is a need for further reports and studies with greater evidence, in order to demonstrate the validity of this treatment.

Keywords - Osteonecrosis; Knee, Athletes

\section{INTRODUCTION}

Ahlbäck et $\mathrm{al}^{(1)}$ described knee osteonecrosis as a distinct clinical entity in 1968. It is a clinical syndrome characterized by bone necrosis of a load-bearing portion of the femoral condyle, followed by subchondral fracture, subsequent segmental collapse and arthrosis.

Osteonecrosis may be associated with a variety of medical conditions, such as alcoholism, corticosteroid use, hyperuricemia, Gaucher's disease, sickle cell anemia, familial pancreatitis, hyperlipidemia and Cushing's syndrome. The etiological basis for spontaneous osteonecrosis is unknown. The theories include vascular insufficiency or microfractures of the subchondral plate, with deviation of the synovial fluid from the synovial space to inside the bone. An association between meniscal lesions and osteonecrosis has also been postulated ${ }^{(2,3)}$.

Idiopathic osteonecrosis can also be named avascular necrosis, aseptic necrosis, spontaneous osteonecrosis or Ahlbäck's disease. It generally affects women (3:1) over the age of 55 years (4:1) who are obese $(60 \%)$. Clinically, it is characterized by pain in the knee that starts suddenly without any history of previous trauma, affecting mainly the load-bearing region of the medial femoral condyle. The pain worsens at night, limits physical activity and does not improve with physiotherapeutic treatment or use of nonsteroidal anti-inflammatory drugs ${ }^{(4)}$.

Radiographs initially appear to be normal, and only show changes after two to three months. Scintigraphy with technetium-99m, abnormalities in the affected

1 - Orthopedist and Traumatologist at New World Fracture Hospital; Physician at Atlético Paranaense Soccer Club, Curitiba, PR, Brazil.

2 - Orthopedist and Traumatologist at the Clinical Hospital of the Federal University of Paraná, Curitiba, PR, Brazil.

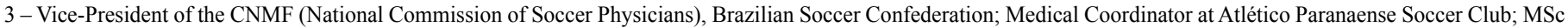
and $\mathrm{PhD}$ in Surgery from IPEM, Evangelical School of Medicine of Paraná, Curitiba, PR, Brazil.

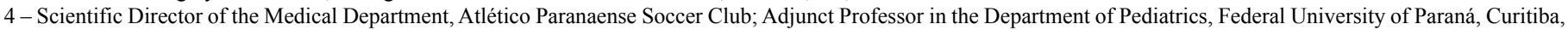
PR, Brazil.

Work performed in the Medical Department of Atlético Paranaense Soccer Club, Curitiba, PR.

Correspondence: Departamento Médico do Clube Atlético Paranaense, Rua Estrada do Ganchinho 1459, Sítio Cercado, 81930-160 Curitiba, PR.

E-mail: edilson.thiele@terra.com.br

Work received for publication: June 16, 2011; accepted for publication: July 12, 2011.

The authors declare that there was no conflict of interest in conducting this work 
condyle are observed. Magnetic resonance imaging (MRI) clearly shows osteonecrosis after 72 hours of evolution. MRI is the preferred method for diagnosing, staging and following up this entity ${ }^{(5,6)}$.

Among the differential diagnoses are pes anserinus bursitis, osteochondritis dissecans, infection, fracture, osteoarthrosis, tumor, neuropathic joint and meniscal lesion.

Osteonecrosis can be classified according to radiographic images of the lesion ${ }^{(7)}$ or according to the arthrosis grading system of Ficat and Arlet ${ }^{(7)}$ or Ahlbäck et al ${ }^{(1)}$. The classification of Ficat and Arlet ${ }^{(7)}$ establishes four stages:

- Stage I - knees with normal appearance;

- Stage II - knees with cystic or sclerotic lesions, or both, normal outline of the tibia and/or femur and absence of subchondral fractures or flattening of the joint surface;

- Stage III - knees with crescent sign and subchondral collapse;

- Stage IV - knees with reduced joint space; presence of cysts and osteophytes.

The classification of Ahlbäck et $\mathrm{al}^{(1)}$ assesses the degree of arthrosis:

0 - no signs of arthrosis;

1 - diminished joint space;

2 - obliteration of the joint space;

3 - erosion of less than $5 \mathrm{~mm}$;

4 - erosion of between 5 and $10 \mathrm{~mm}$;

5 - erosion of more than $10 \mathrm{~mm}$ and lateral subluxation.

According to the classification of Koshino ${ }^{(8)}$, four radiographic phases can be observed:

1 - Normal radiograph, accompanied by pain;

2 - Avascular appearance, with presence of oval-shaped radiotransparent lesion and normal cartilage;

3 - Subchondral collapse and a subchondral radiolucent zone (linear or cystic);

4 - Degeneration, osteophytes and sclerosis (Figure 1).

The evolution depends on the size of the area affected. Lesions with areas larger than $5 \mathrm{~cm}^{2}$ have a worse prognosis ${ }^{(9)}$.

In relation to the treatment, there is still some controversy, especially regarding patients in phase III. The phases include:

Phases I and II - benign conservative treatment: corticoid infiltration is not indicated, but arthroscopic perforation or meniscectomy can be performed to correct degenerative lesions;

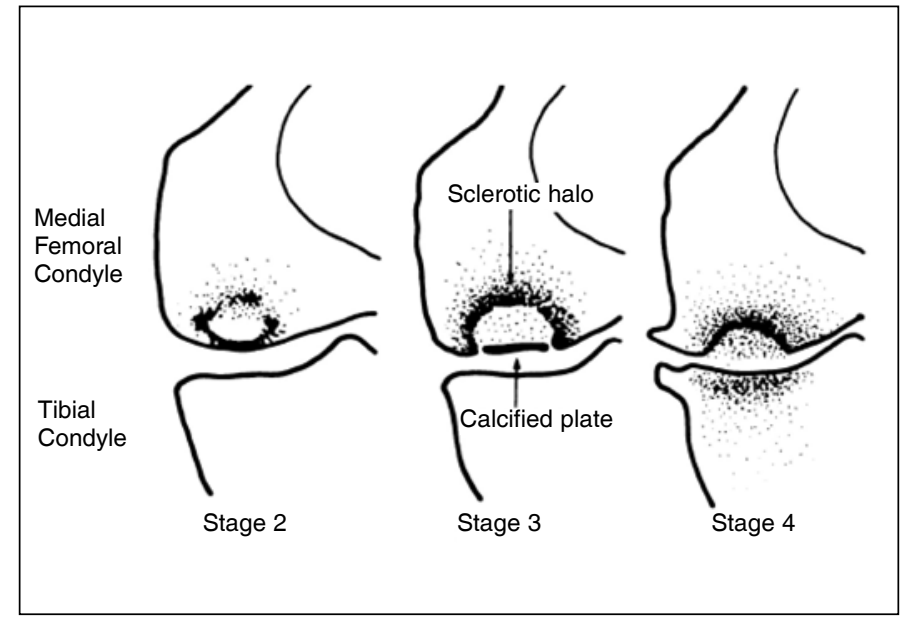

Figure 1 - Koshino classification.

Source: Koshino T. The Treatment of Spontaneous Osteonecrosis of the Knee by High Tibial Osteotomy With and Without Bone-Grafting or Drilling of the Lesion. J Bone Joint Surg Am. 1982;64:47-58(8).

Phase III - focus of controversy, but Mont et al ${ }^{(10)}$ suggested that conservative treatment should be implemented initially for patients in phase III, with little need for surgical treatment on a second occasion;

Phase IV - surgical treatment.

Conservative treatment consists of using walking sticks or crutches, NSAIDs and analgesics to relieve night pain. Today, an innovative method involving a hyperbaric chamber is being used, and this has been presenting good results ${ }^{(11)}$.

The surgical procedures possible are:

1 - Osteotomy;

2 - Perforation of the lesion;

3 - Bone grafting;

4 - Arthroplasty.

\section{Clinical case: knee osteonecrosis - October 11, 2010}

A 24-year-old male patient who was a professional soccer player presented a complaint of pain in his right knee, one day after physical activity (soccer match on June 5, 2010). He reported suffering a slight trauma in hyperextension during the start of the game, but continued in the match without problems. On the next day, he complained of pain in his right knee.

Physical examination showed joint effusion, diffuse pain on palpation of the medial region of the knee, negative ligament maneuvers and a McMurray maneuver that was doubtful for the medial meniscus.

The radiographic examination was normal, and MRI showed a focal area of subchondral bone edema in the region of the medial femoral condyle (Figure 2).

The initial treatment included physiotherapy (TENS, ultrasound, cryotherapy and non-impact 
activities e.g. on a bicycle or in a swimming pool and the support was withdrawn. The player was released for the holiday at the start of the World Cup. At a return visit on July 13, 2010 (38 days of evolution), the player reported that there had been partial pain improvement, but that he remained off training and games, receiving physiotherapeutic treatment.

With evolution, a new control MRI examination was requested, which showed small-scale joint effusion and a subchondral fracture of the bone marrow in the load-bearing area of the medial femoral condyle, with extensive edema of the adjacent bone marrow (Figure 3).

Physiotherapeutic treatment was continued in two shifts for 30 days, and Miacalcic ${ }^{\circledR}$ (Calcitonin, 20 UI subcutaneously), calcium carbonate and cholecalciferol were administered. This led to an improvement of the condition, and the player was released for training (76 days after the injury). However, the player was unable to run because the pain returned.

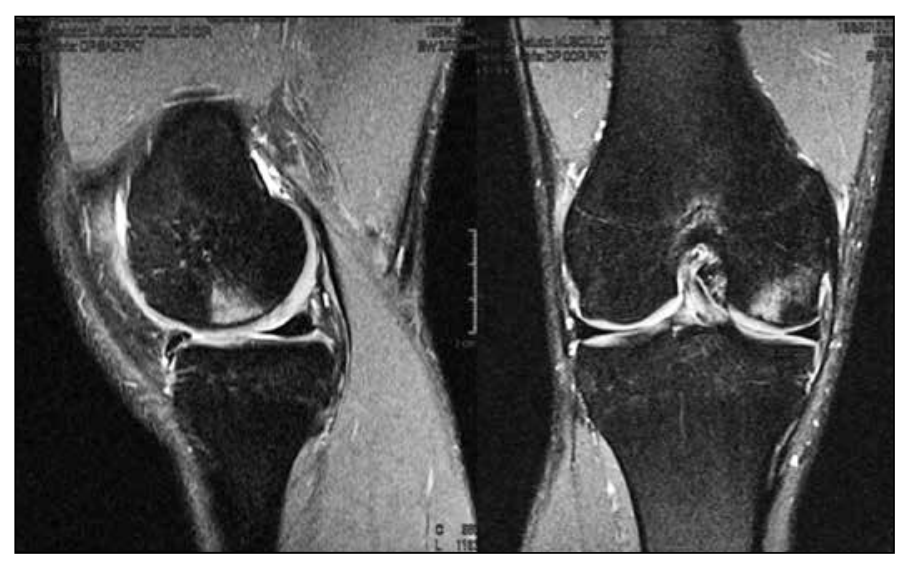

Figure 2 - MRI on June 16, 2010 (first control). Source: Personal files.
On August 21, a new MRI examination showed a small-scale joint effusion with findings compatible with a hypothesis of sequelae from a subchondral microfracture in the weight-bearing area of the medial femoral condyle. In comparison with the previous examination, there was a marked reduction in the bone edema at this condyle (Figure 4).

The player continued to have a complaint of pain, even though he was undergoing physiotherapeutic treatment in two shifts. He started to receive acupuncture treatment (August 27), with partial improvement. After two weeks, he reported that there had been a significant improvement and was released to undergo supervised training. However, he abandoned this due to claudication, with a complaint of incapacitating pain in his knee, even though this was 90 days after the symptoms had started.

On September 16, a new MRI examination was performed. This showed a small-scale joint effusion and mild chondropathy in the weight-bearing area of the medial femoral condyle. In comparison with the preceding examination, a significant reduction in edema in the trabeculated bone was observed (Figure 5).

With the patient's persistent complaint of pain in his right leg, bone scintigraphy was requested on September 20. The report from this revealed that there was an increased rate of bone remodeling in the right knee, which was most evident on its medial face, with a slight associated inflammatory process (Figure 6).

Treatment using a hyperbaric chamber and sodium ibandronate $\left(\right.$ Bonviva $\left.^{\circledR}\right)$, which is a bone resorption inhibitor, was started. The treatment chosen included

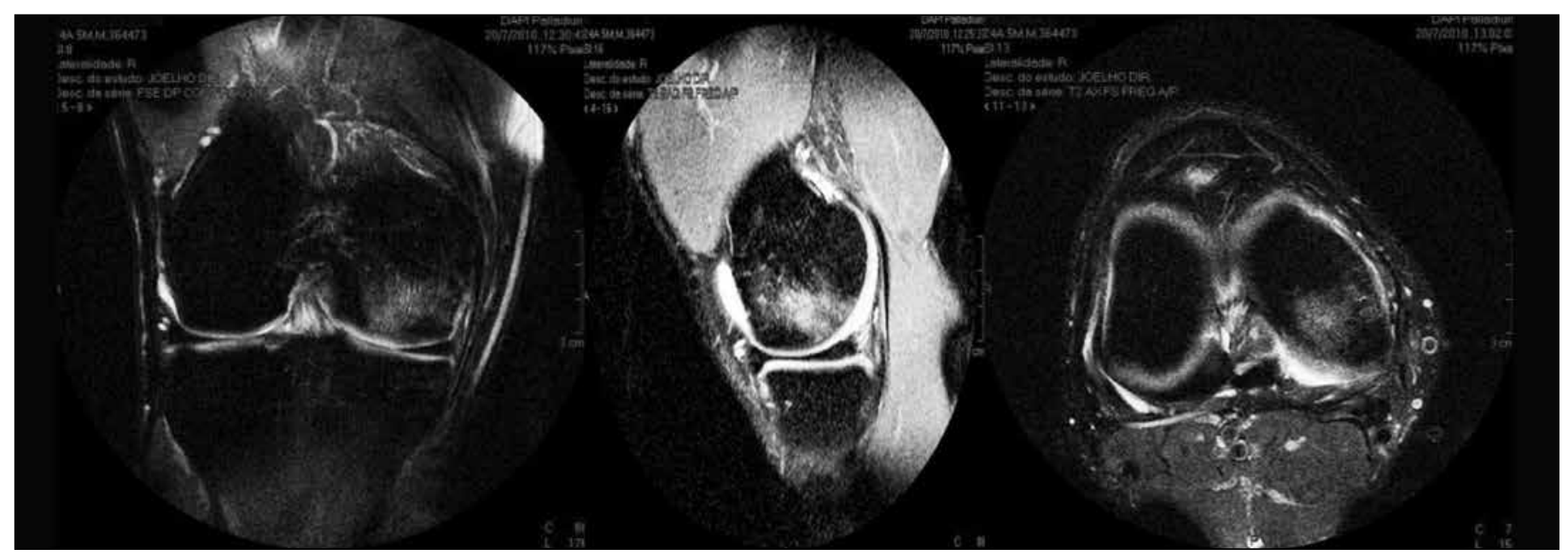

Figure 3 - MRI on July 20, 2010 (second control). 


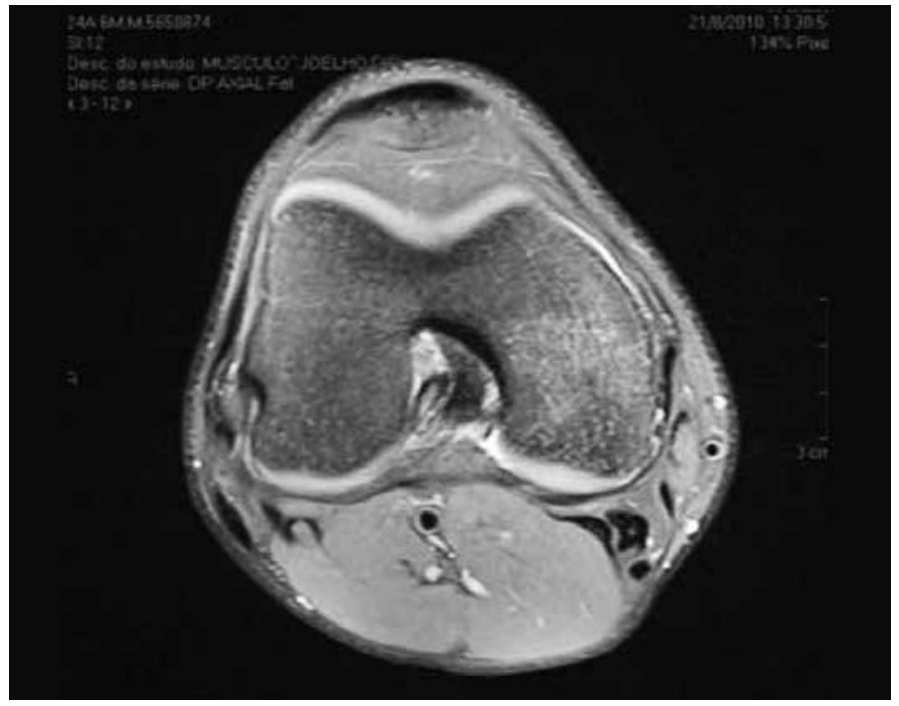

Figure 4 - MRI on August 21, 2010 (third control). Source: Personal files.

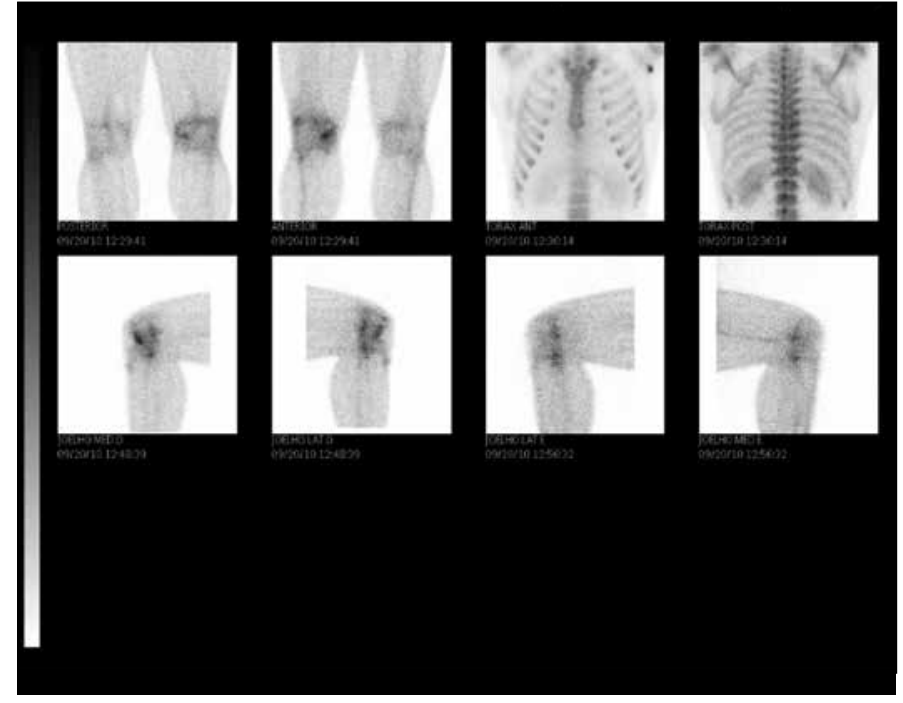

Figure 6 - Bone scintigraphy on September 20, 2010.

Source: Personal files.
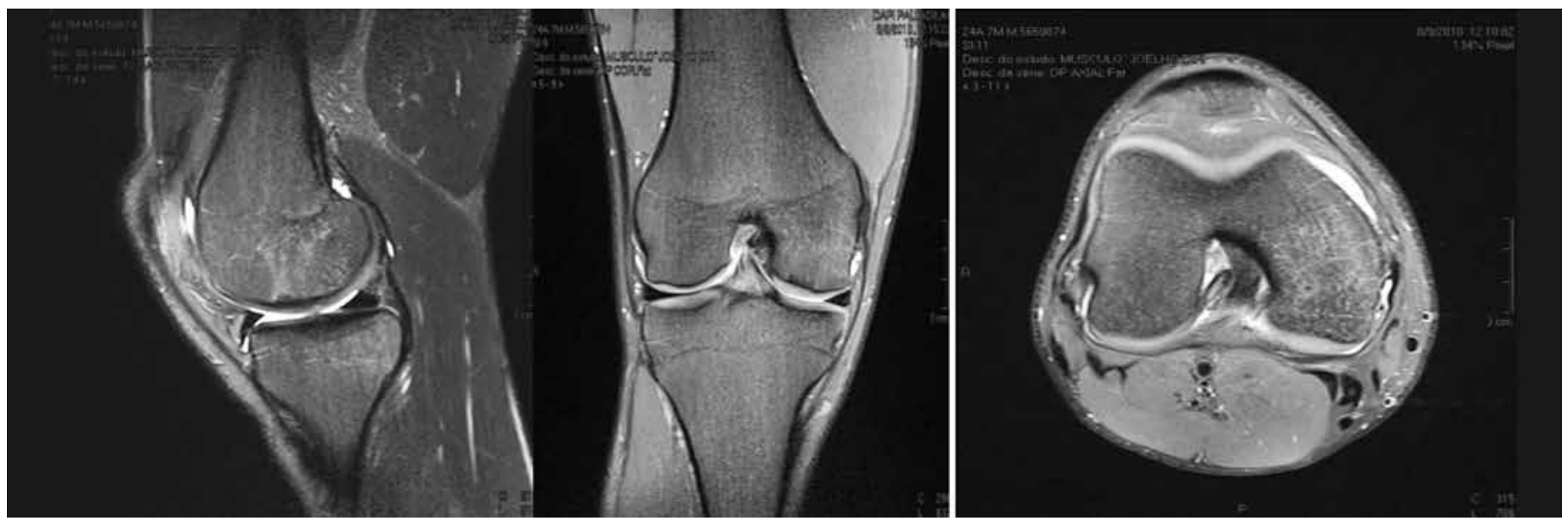

Figure 5 - MRI on September 16, 2010.

Source: Personal files.

removal of weight-bearing, oral medication and use of a hyperbaric chamber for 10 sessions. Clinically, the patient presented a significant improvement. His progressive definitive return to training was finally achieved more than 110 days after the symptoms started, which for a professional soccer player is a very long time, despite all the care that was taken after the case had been diagnosed.

\section{DISCUSSION}

The treatment of spontaneous osteonecrosis is a controversial subject. Koshino et $\mathrm{al}^{(12)}$ emphasized the need for assessment of the cartilaginous coating by means of arthroscopy before instituting treatment.

Several studies have provided backing for indicating conservative treatment when the cartilage is com- plete. Muheim and Bohne ${ }^{(9)}$ recommended conservative treatment in stages 1 and 2, when the lesion might stabilize and the patient might become asymptomatic.

Today, new medications are being used with new and encouraging results. Alendronates are being used for treating femoral osteonecrosis with promising results with regard to avoiding the collapse of the femoral head in situations of osteonecrosis, as demonstrated by Lai et $\mathrm{al}^{(13)}$. Kraenzlin et $\mathrm{al}^{(14)}$ found good results with diminished pain and bone edema in cases of osteonecrosis of the femoral condyle.

Although Koshino ${ }^{(8)}$ and Lotke et $\mathrm{al}^{(15)}$ supported the need for an arthroscopic diagnosis, they stated that curettage, arthroscopic debridement and meniscectomy were contraindicated since they could trigger or worsen the osteonecrosis and were triggering factors for osteoarthritis. 
Muheim and Bohne ${ }^{(9)}$ emphasized that osteotomy was necessary in knees with an angular deviation. Lotke et $\mathrm{al}^{(15)}$ and several other authors indicated osteotomy in situations of deviation of the lower limb from the axis, and arthroplasty in cases with late development, when degenerative lesions develop over an area greater than $50 \%$.

Treatment using a hyperbaric chamber is a recently introduced method and has shown promising results. It was used initially for treating osteonecrosis of the femoral head ${ }^{(10)}$. It gives rise to improvement in most patients with grade II, not only in their symptoms but also in their radiographic assessments ${ }^{(16)}$.

Independent of the treatment, osteonecrosis is associated with a poor prognosis, especially when the initial size of the lesion was greater than $5 \mathrm{~cm}^{2}$. Koshino et $\mathrm{al}^{(12)}$ and Lotke et $\mathrm{al}^{(15)}$ also affirmed that the prognosis for the disease depended on the size of the initial lesion. Lesions of area less than $3.5 \mathrm{~cm}^{2}$ have a good prognosis, whereas those greater than $5 \mathrm{~cm}^{2}$ have a poor prognosis, with a poorly defined zone between these two values. The ratio between the widths of the lesion and the condyle has been used as a parameter for the prognosis: lesions larger than $50 \%$ are related to poor prognosis ${ }^{(17)}$.

\section{REFERENCES}

1. Ahlbäck S, Bauer GC, Bohne WH. Spontaneous osteonecrosis of the knee Arthritis Rheum. 1968;11(6):705-33.

2. Norman A, Baker ND. Spontaneous osteonecrosis of the knee and medial meniscal tears. Radiology. 1978;129(3):653-6.

3. Nakamura N, Horibe S, Nakamura S, Mitsuoka T. Subchondral microfracture of the knee without osteonecrosis after arthroscopic medial meniscectomy. Arthroscopy. 2002;18(5):538-41.

4. Amatuzzi MM, Albuquerque RFM, Prada FS. Osteonecrose Idiopática do JoeIho. Rev Bras Ortop. Rev Bras Ortop. 2003;38(3):73-81,

5. Resnick D, Kang HS. Internal derangements of joints: emphasis on MR Imaging. Philadelphia: Saunders; 1997.

6. Yates PJ, Calder JD, Stranks GJ, Conn KS, Peppercorn D, Thomas NP. Early MRI diagnosis and non-surgical management of spontaneous osteonecrosis of the knee. Knee. 2007;14(2):112-6.

7. Ficat RP, Arlet J. Functional investigation of bone under normal conditions. In Ischemia and necrosis of bone. Hungerford DS, editor. Baltimore: Williams and Wilkins, 1980. p. 29-52.

8. Koshino T. The treatment of spontaneous osteonecrosis of the knee by high tibial osteotomy with and without bone-grafting or drilling of the lesion. J Boné Joint Surg Am. 1982;64(1):47-58.

9. Muheim G, Bohne WH. Prognosis in spontaneous osteonecrosis of the knee. Investigation by radionuclide scintimetry and radiography. J Bone Joint Surg Br. 1970;52(4):605-12.
Yates et $\mathrm{al}^{(6)}$ used MRI to evaluate the evolution of patients with osteonecrosis and reached the conclusion that the presence of high uptake in T2 along with length greater than $14 \mathrm{~mm}$ and depth greater than 4 $\mathrm{mm}$ from low $\mathrm{T} 2$ signal did not necessarily indicate a poor prognosis.

The literature also indicates that poor results, which reflect physicians' and patients' disappointment, may be related to physician's lack of capacity to take control over the symptoms of the disease or a lack of cooperation from patients during the first six months of the disease $\mathrm{e}^{(1,10,11,16)}$.

Although hyperbaric chambers are a new treatment method, use of this method in association with drug therapy and removal of weight-bearing may bring good results in treating idiopathic osteonecrosis, even in sports players with high physical demands. However, there is a need for new reports and studies with further evidence, in order to demonstrate the validity of this method.

It should also be highlighted that, even among highperformance sports players with very well exercised muscle groups, this pathological condition maintains a certain pace of evolution. Thus, early diagnosis and treatment are important and may avoid significant sequelae for soccer players.

10. Mont MA, Baumgarten KM, Rifai A, Bluemke DA, Jones LC, Hungerford DS. Atraumatic osteonecrosis of the knee. J Bone Joint Surg Am. 2000;82(9):1279-90.

11. Reis ND, Schwartz O, Militianu D, Ramon Y, Levin D, Norman D, et al. Hyperbaric oxygen therapy as a treatment for stage-I avascular necrosis of the femoral head. J Bone Joint Surg Br. 2003;85(3):371-5.

12. Koshino T, Okamoto R, Takamura K, Tsuchiya K. Arthroscopy in spontaneous osteonecrosis of the knee. Orthop Clin North Am. 1979;10(3):609-18.

13. Lai KA, Shen WJ, Yang CY, Shao CJ, Hsu JT, Lin RM. The use of alendronate to prevent early collapse of the femoral head in patients with nontraumatic osteonecrosis. A randomized clinical study. J Bone Joint Surg Am. 2005;87(10):2155-9.

14. Kraenzlin ME, Graf C, Meier C, Kraenzlin C, Friedrich NF. Possible beneficial effect of bisphosphonates in osteonecrosis of the knee. Knee Surg Sports Traumatol Arthrosc. 2010;18(12):1638-44.

15. Lotke PA, Ecker ML, Barth P, Lonner JH. Subchondral magnetic resonance imaging changes in early osteoarthrosis associated with tibial osteonecrosis. Arthroscopy. 2000;16(1):76-81.

16. Fuchs D. Avascular necrosis of the knee and hyperbaric oxygen therapy. ISAKOS Newsletter, 2010. Disponível em: http://www.isakos.com/assets/ newsletter/sum10.pdf

17. Lotke PA, Abend JA, Ecker ML. The treatment of osteonecrosis of the medial femoral condyle. Clin Orthop Relat Res. 1982;(171):109-16. 